\title{
A Study on the Organization Structure of Third-party \\ Logistics Enterprise Servicing for Manufacturing Enterprise
}

\author{
Xiaoye Zhou \\ School of Management, Shenyang University of Technology \\ No.111, Shenliao West Road, Economic \& Technological Development Zone \\ Shenyang 110178, China \\ Xiuyi Xie \\ School of Management, Shenyang University of Technology \\ No.111, Shenliao West Road, Economic \& Technological Development Zone \\ Shenyang 110178, China \\ E-mail: xiexiuyiqiliang@163.com
}

The research is financed by Social sciences natural fund of Liaoning Province, No. L07DJY097

\begin{abstract}
This paper introduces ways and advantages of third-party logistics enterprise servicing manufacturing enterprise, analyses supply-chain of manufacturing enterprise and further studies for the organization structure of third-party logistics enterprise servicing manufacturing enterprise, to seek to the enterprise organization structure which has the best combination in third-party logistics enterprise with manufacturing enterprise.
\end{abstract}

Keywords: Third-party logistics enterprise, Manufacturing enterprise, Organization structure

\section{Current Situation of Foreign Funds in China Insurance Industry}

Following the rapid development of third-party logistics enterprises and industrial structure entering the mid-term of industrialization in our country, the demand which logistics function is stripped from manufacturing industry is very intense. It becoming one of the necessary considering questions and one of the most effective way to wealth for more and more third-party logistics enterprises to servicing manufacturing enterprise. In sharping competition, logistics enterprises for enhancing the competitive power have began to innovate in technology, service, management and other aspects. But the most of third-party logistics enterprises in our country have been restructured from the traditional logistics enterprises, haven't enterprise organization structure matching to the characteristics of third-party logistics servicing manufacturing enterprise. In a great extent, it restricts the servicing efficiency of third-party logistics for manufacturing enterprises.

The promoting action of third-party logistics enterprises to manufacturing enterprises is following several aspects: (1) specializing service and reducing the cost; (2) making manufacturing enterprises concentrate in developing their core business; (3) improving the operating flexibility of manufacturing enterprises; (4) reducing supervisory cost of manufacturing enterprises; (5) reducing the operating dangerous of manufacturing enterprises; (6) improving the customer servicing level of manufacturing enterprises; (7) promoting the manufacturing enterprise image. (Donald, 2002, 169)

This paper, through analyzing organization structure of third-party logistics enterprises, researches the enterprise organization structure having the best bonding point between third-party logistics enterprises and manufacturing enterprises. It improves the servicing level of third-party logistics enterprises for manufacturing enterprises and realizes two-to-win and common development.

\section{Service Modes of Third-Party Logistics Enterprises Servicing for Manufacturing Enterprises}

"third-party logistics", in National standards "logistics terminology", is defined that "third-party logistics is the business mode of logistics services provided by logistics except supplier and demander".

Service modes of third-party logistics enterprises servicing for manufacturing enterprises is following several aspects. 
(1) Third-party logistics enterprises provides service for manufacturing enterprises through taking the outsourcing of transportation, warehousing and other functions.

This is the fundamental level of logistics outsourcing. Manufacturing enterprises may consider to accredit transportation and warehousing which appropriates many source to one or several large-scale third-party logistics enterprises. They needn't build the relaxed information system web. That is better to the concentrative development of core ability.

(2) Third-party logistics enterprises provide service for manufacturing enterprises through taking the outsourcing of their internal logistics.

Manufacturing enterprises are just responsible for the action on product line, accredit the excellent Third-party logistics enterprises with materials out of storehouse, manufactured goods entering storehouse and other related processes. It may ensure the logistics specialization and efficiency of manufacturing enterprises, be better to the radical transformation of enterprise operating processes. (Linyong, 2007, 334-340). But simultaneously, manufacturing enterprises must pay large cost to realize it. So third-party logistics enterprises should have comparative strength and reliability.

(3) Third-party logistics enterprises provides service for manufacturing enterprises through taking the outsourcing of their logistics planning design and information management.

This is strategic cooperation based non-business layer. Manufacturing enterprises may replan and design the enterprise logistics operations with aid in professional talent and management experience of Third-party logistics enterprises. As for Third-party logistics service providers, updating and maintaining information system is necessary, is one of their core operations. So it nearly needn't be paid any extra cost, and promotes to realize two-to-win and common development.

(4) Third-party logistics enterprises provides service for manufacturing enterprises through taking the outsourcing of all their external logistics functions.

Third-party logistics enterprises provides service for manufacturing enterprises through taking the multi-level outsourcing strategy of manufacturing enterprises. Manufacturing enterprises strips all their external logistics function from their producing functions. This is the high level outsourcing. To a great extent, this mode may reduce the stock dangerous of manufacturing enterprises, even realize zero stock. On the other hand, with aid in the advanced and professional service system of third-party logistics enterprises. This mode may shorten production cycle of manufacturing enterprises, accelerate cash flow, promote service quality. The building of this function stripping process must base on supply-chain strategic association, simultaneously set the high request to the operating ability and supporting ability of information system of third-party logistics enterprises.

\section{Analysis of Organization Structure of Third-Party Logistics Enterprise Servicing for Manufacturing Enterprises}

Through analysing the supply-chain of manufacturing enterprises, we can see that manufacturing industry have its' particularity difference from other industries. So third-party logistics enterprise servicing manufacturing enterprises should have very strong flexibility and the ability of rapid reaction. Combining the characteristics of manufcturing enterprises, this paper carries out the introduction and the analysis the following several the organization structure models of third-party logistics enterprise.

\subsection{Class Matrix Type Logistics Organization Structure}

The design of Class Matrix logistics organization structure intruduces the item management into the operation of logistics activity. Because of the personalization of customer logistics demand, Class Matrix logistics organization structure is particularly suitable to the operating mode of item management. Class Matrix logistics organization structure is shown in figure 1.

According to the character and service range of manufcturing enterprises, the flexibility of Class Matrix logistics organization structure is quite strong. Because the transverse item unit may momentarily build, adapt and cancel according to requires. This kind of structure is in favor of the enough use of resources, in favor of strengthening the transverse relationship between departments, in favor of unifying administration and account management, in favor of concentrating attention on the vital strategic questions. So this kind of structure is better at fitting for the third-party logistics enterprises servicing manufcturing enterprises which have moderate business field, moderate service range and moderate scale.

\subsection{Mixed Network Type Logistics Organization Structure}

The design of Mixed network type logistics organization structure have the excellentces both centralized type of organization and decentralization of authority. Every branches's customers come from two parts. One part of customers comes from headquarter, is managed according to the cost center partern; the other part of customers is developed and 
managed according to the profit center partern. Mixed network type logistics organization structure is shown in figure2.

Large-scale international manufacturing enterprises need global logistics distribution and service. Mixed network type logistics organization structure is both in favor of macro-planning of the headquarters and in favor of keeping the relative independence of branches. This kind of structure, through co-marketing between headquarters and every branch, greatly enhances the marketing level of the whole company, simultaneously has better responsible ability. (Niu Sihu, 2008, p.195-197). So this kind of structure is more fitting for the third-party logistics enterprises providing service for manufcturing enterprises which need strongly comprehensive strength, broad region and large scale.

\subsection{Distributed Network Type Virtual Logistics Organization Structure}

Distributed network type virtual logistics organization structure is shown in figure 3. From the figure, we can see that managers take the logistics basic activities to external forces. The organization core consists of cost control center and information center of the alliance which conposes of third-party logistics enterprise, carries out design, organization, surveillance and control directed at logistics activities.

Non-assets logistics service is better at enhancing profit ability and profit speed than assers logistce service. Investigation and study going deep into manufcturing enterprise is in favor of realizing the co-operation with manufcturing enterprises from strategic level. This kind of structure is mini-scale, not hardware facilities, but have advanced logistics management technology and information technology. It can help manufcturing enterprises working out marketing plan, transportation plan, order plan, production plan; even to carry out reforming enterprise process. (Linyong, 2007, p.341-346) When manufcturing enterprises alter their production plane according to market change, logistics enterprises can rapidly transmit information, work out elastic plan, and adjust all links correspondingly. Above all can deepen the bilateral cooperation to a great extend, enable the third-party logistics service provider to occupy more and more important and stable position in the entire production.

\subsection{Front-Back-End Type Logistics Organization Structure}

In this kind of structure, front-end is CRM customer relationship management system and the conformity of enterprise and market, back-end is ERP system and the conformity of point-of-purchase and each of enterprise eternal points. Both front-end and back-end are in the whole system, just like that CRM or ERP is only subsystem of large system, service for system integrity. Front-back-end type logistics organization structure is shown in figure 4.

The final function which third-party logistics enterprises provide service for manufcturing enterprises guarantees the efficient operation of manufacturing industry and the optimization of supply-chain management. This kind of structure is the new organizational structure which has both the flexibility of small enterprise and the resource advantage of large enterprise (Xu Zhifen, 2007, p.9-12). It may maximize to provide value-added service to a great extend and really reflect "customer-centric" organization structure. So this organization structure is fitting for third-party logistics enterprise providing service for the manufcturing enterprises which have special demand, customers and service is special important to.

\section{Conclusion}

Third-party logistics at home and abroad rapidly develops. The organization structure as the link between enterprise strategy and its carring out is facing to the challenge which is coming from marketing competition. According to the supply chain of manufcturing enterprises, this paper, just combing the service characteristics of manufcturing enterprises needing and the service way of third-party logistics enterprise, has carried on generally analyzing to third-party logistics organization structure. However, according to the difference of service type, service way, service range, service field and other special requirements, the same kind of third-party logistics organization structure maybe has great diversity. Therefore, the design of third-party logistics organization structure servicing manufcturing enterprises should be considering of time, field, the special situations of manufacturing enterprise.

\section{References}

Donald J. Bowersox, David J Closs, \& M Bixby Cooper. (2002). Supply Chain Logistics Management. New York: McGraw-Hill, (Chapter 4).

Lin Yong \& Man Shihua. (2007). Fundamentals of Logisstics Management. Wuhan: Huazhong University of Science and Technology. 334-346.

Liu Meng, Lan Bihua, Gao Benhe., \& Liu Dacheng. (2006) The developing way of the combination of Third-party Logistics and Manufacturing Indusry. Chinese-foreign logistics, 8, $22-23$.

Niu Sihu. (2008). The Developing Countermeasures and Advices of Third-party Logistics Service of Liaoning Manufacturing Indusry. Commercial Research, 7,195-197.

Xu Zhifen., \& Qi Anbang. (2007). Study on the Organization Mode of 3PL Enterprises Based on Project Management. Logistics Technology, 12, 9-12. 


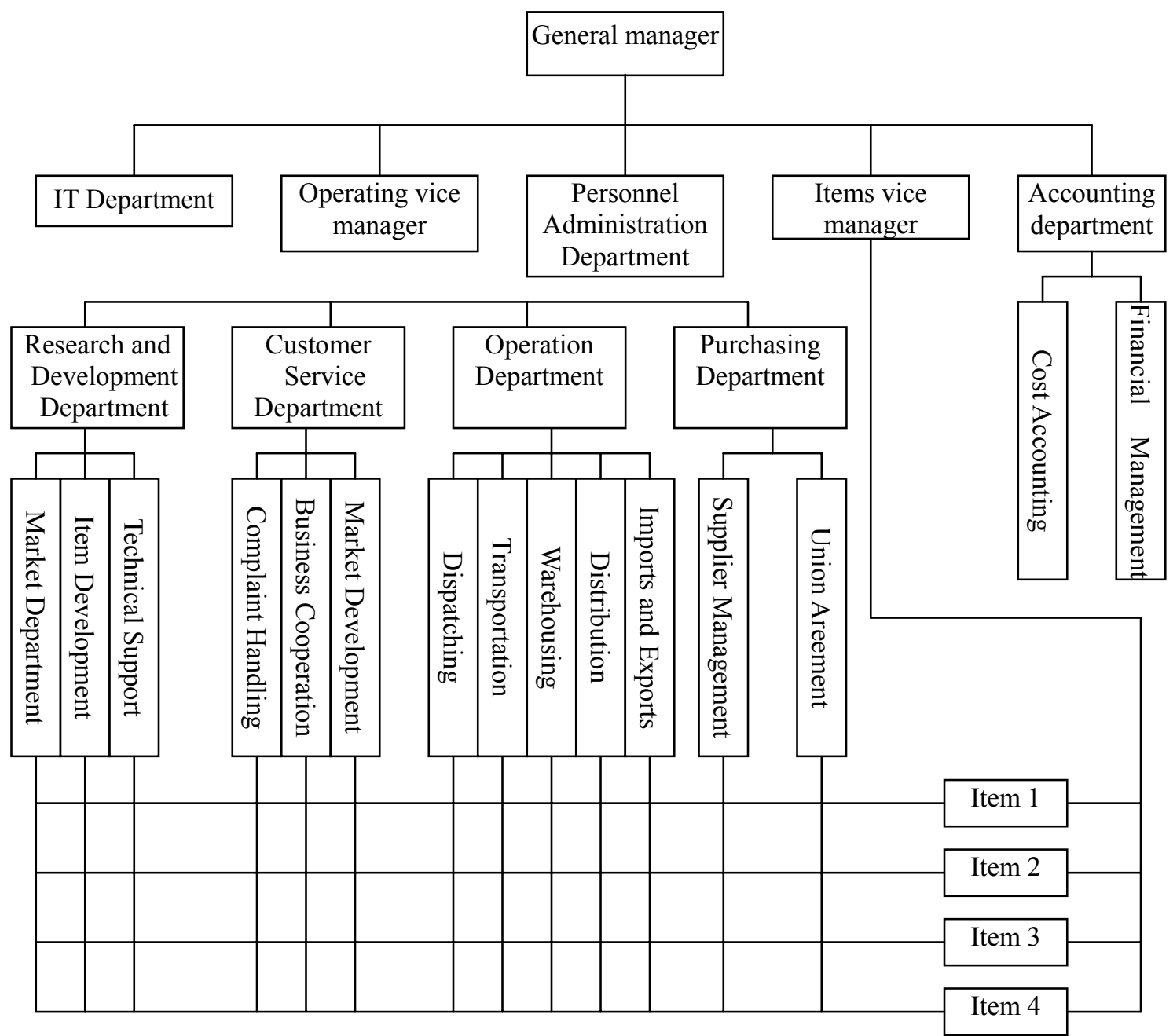

Figure 1. Class Matrix logistics organization structure

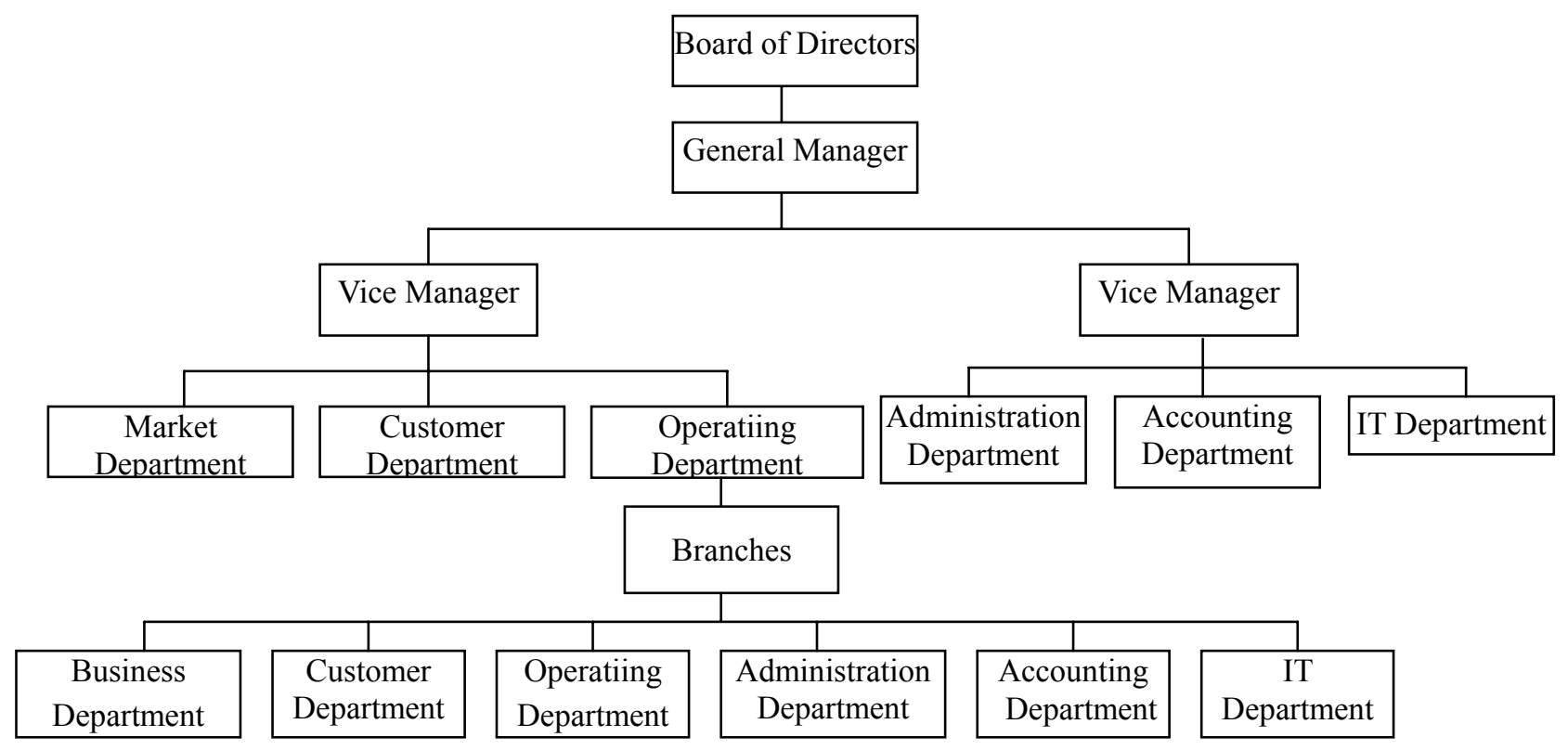

Figure 2. Mixed network type logistics organization structure 


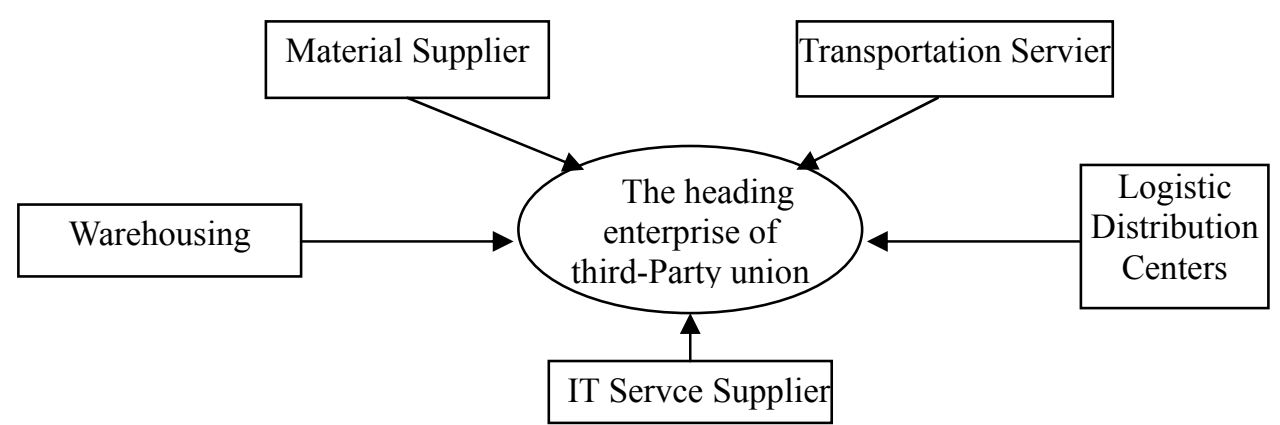

Figure 3. Distributed network type virtual logistics organization structure

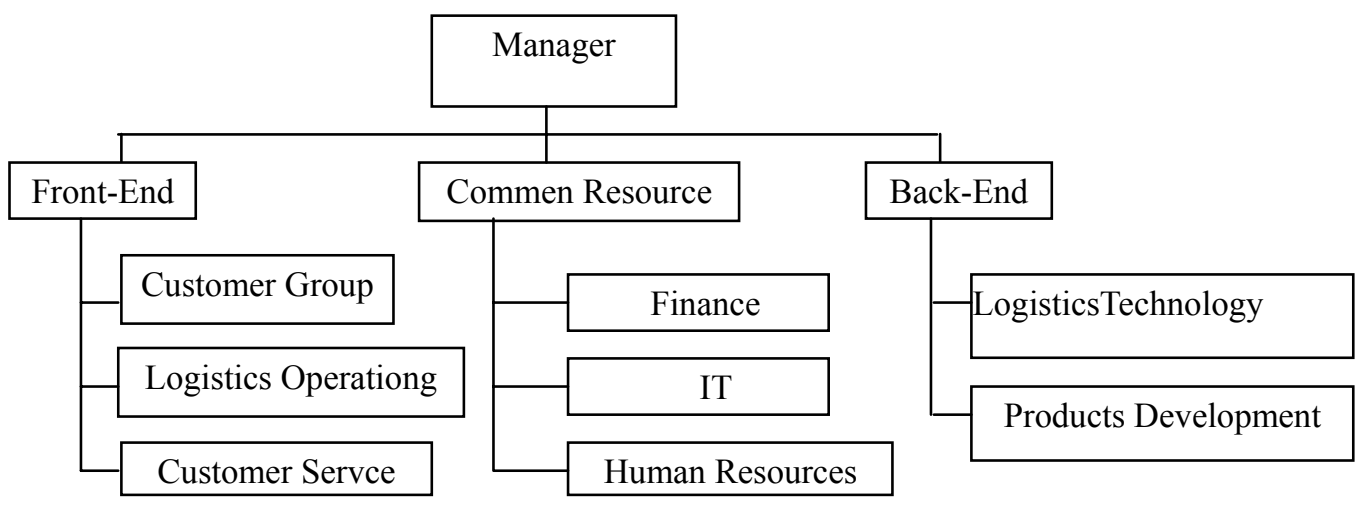

Figure 4. Front-back-end type logistics organization structure 